\title{
NORMAS - O ESTABELECIMENTO dos Direitos Humanos
}

\author{
Clélia Aparecida Martins ${ }^{1}$
}

\begin{abstract}
RESUMO: Habermas entende os direitos humanos como produtos do mundo da vida; e é no interior do debate público, com a participação efetiva dos cidadãos, que deve ocorrer a produção deles como normas e princípios. A questão central abordada inicialmente no texto concerne ao status dessas normas e ao seu modo de instituição, dependente das relações de reciprocidade entre os sujeitos. Uma vez que, em sociedades complexas, apenas idealmente parece ser possível sustentar a participaçáo de todos os sujeitos no processo de elaboraçấo de normas, o texto procura analisar a viabilidade da concepção de Habermas. Ao considerar os elementos conceituais que orbitam essa questão, processa-se no curso do texto um deslocamento para outra, a saber, a relativa ao quanto o modo de sustentaçáo da normatividade jurídica de um ordenamento social o determina como democrático ou não. Este é o ponto decisivo ao tratamento das normas relativas aos direitos humanos: a análise de Habermas é ideal, mas o pêndulo entre moral e empiria se mantém sempre, de modo que, pelo escopo conceitual, se não há como confirmar a identificação entre legitimidade dos direitos humanos e direitos humanos produzidos democraticamente, torna-se impossível querer negá-la.
\end{abstract}

PALAVRAS-CHAVE: Jürgen Habermas. Direitos humanos. Normas. Reciprocidade.

O conceito clássico de integração, o de integração normativa, relativo à "[...] integraçáo simbólica por meio de normas"; ${ }^{2}$ continua preciso e, na medida em que fins e objetivos designados por princípios adquirem realidade objetiva, torna-se paulatinamente relevante, a qualquer comunidade linguística voltada a manter sua integração, questionar-se sobre quais normas a levam a defender e submeter-se a este ou aquele princípio e não a outro. Logo, a definição de

\footnotetext{
${ }^{1}$ Docente do Departamento de Filosofia da Faculdade de Filosofia e Ciências da UNESP - Marília; líder do Grupo de Pesquisa: “Filosofia contemporânea: Habermas". E-mail: clelia@marilia.unesp.br

${ }^{2}$ GEHARDT, V. Menschenrechte und Rhetorik, p. 20.
} 
integração, apesar de clássica, é variada para cada comunidade e o foco, não deve estar nas normas, mas no processo de escolha delas. Aqui entra o papel do acordo em torno de uma justificação racional das normas com validade universal. A análise sobre produção de normas a partir de acordos (consensos) fundados em proferimentos válidos constitui a primeira parte deste texto.

Para Habermas, todo acordo deve ser acompanhado do reconhecimento mútuo baseado na reciprocidade. Apesar de, no seu entendimento, as instituiçóes e os sistemas de ação ${ }^{3}$ estarem muito mais estruturados que a pluralidade de ideias e convicçóes as quais possam estar presentes no mundo da vida, tal como Rawls, ele também defende ser preciso resgatar a necessidade de um reconhecimento recíproco racional por parte dos agentes morais como fundamento essencial para a construçáo de acordos mantenedores de ordenamentos legítimos. Isso exigiu uma análise da categoria habermasiana de reciprocidade, a qual constitui o segundo momento deste texto. Exposta essa categoria, no entanto, percebe-se que ela náo dilui - quando muito apenas atenua - o problema central e tema deste texto, a saber: como, no marco de uma cultura política que admite de fato a coexistência de uma pluralidade de convicções valorativas, direitos humanos concebidos de maneira teóriconormativa podem ser pré-estabelecidos sem oferecer riscos para a vida democrática da cidadania? A última parte do texto procura na filosofia de Habermas uma resposta a essa questáo.

\section{I - NORMAS, ACORDO E PRETENSÓES DE VALIDADE}

As normas enunciam os comandos, os imperativos, sob forma genericamente inteligível, mas sua inteligibilidade requer, mesmo como forma, uma referência ao conjunto de condiçôes e ingredientes que dáo à ordem jurídica um senso próprio - e nesse conjunto estão os valores. Elas apresentam um sentido deontológico - a validade deontológica delas obriga indistintamente todos os destinatários -, enquanto os valores apresentam um sentido teleológico, traduzem preferências compartilhadas e admitem concordância parcial. Essa diferença permite a Habermas considerar os direitos humanos como normas legais constituídas e, enquanto tal, formadas segundo o modelo de normas de ação obrigatórias. A obediência a normas só "exigível

\footnotetext{
${ }^{3}$ FG 84, t. 88. Exceto "Entgegnung", todos os demais textos de autoria de Habermas são referidos com as letras iniciais do título em alemão, seguidas do número da página no original e na tradução em português, a qual é precedida da letra " $\mathrm{t}$ ".
} 
quando elas atingem o nível da obrigatoriedade jurídica”, ${ }^{4}$ não implicando necessariamente a aplicação delas. Desde o conceito de integridade do direito tomado por Habermas de Dworkin, ${ }^{5}$ no plano da justificação, normas ou princípios < Grundsätze> não precisam ser concebidos como contraditórios, mas devem ser vistos como concorrentes no plano de sua aplicação, pois ambos possuem uma força de justificação maior que a de valores, porque podem pretender uma obrigatoriedade geral, embora eles se revelem apenas mediante a interpretaçáo.

A questão é o que deve ser feito em uma situação na qual não está claro quais normas são ou não apropriadas para solucionar um caso de conflito, ou para estabelecer uma regra etc., ou como deve ser avaliada uma situaçáo em que é questionada a validade de suas normas - validade agora carece de fundamentação e de aplicaçấo imparcial, pois se perdeu ou deixou de existir a crença na validade e adequação de normas pré-determinadas. Devido à perda de fundamentos absolutos da ética, os pontos de vista morais têm "[...] de permanecer na prática sem conseqüências", se não contarem com a “[...] força impulsionadora dos motivos e com a validade, social e reconhecida, das instituições", e o processo de validação de normas deve "[...] enfrentar o problema de encontrar a forma de evitar [o] passo, inevitável para o trabalho de fundamentação, em direção à dessecularização das normas." ${ }^{\circ}$

No discurso, quando os participantes de uma situação de fala efetivam a tematização da validade das normas e o exame das hipóteses levantadas, concomitantemente ficam enfraquecidas as experiências quotidianas do mundo da vida, a partir das quais não se consegue fundamentar normas válidas universalmente. Nesse estágio, operaçóes abstrativas das morais

\footnotetext{
${ }^{4}$ FG 317, t. 322-331; 567, t. 217 II. Ver também: BAL, Peter. Discourse ethics and human rights..., p. 87. A noção de obrigatoriedade é o princípio formal que, no pensamento habermasiano, assume o caráter de um modelo de comunicação gerador de vínculos interativos estáveis (cf. ED 134-138, t. 133-137). A obrigatoriedade é um distintivo entre normas e valores: "[...] à luz de normas, é possível decidir o que é mandado fazer; no horizonte dos valores, qual comportamento é recomendável.” (FG 312, t. 317 I). Ao contrário das normas, os valores "[...] concorrem para obter primazia; na medida em que encontram reconhecimento intersubjetivo no âmbito de uma cultura ou forma de vida, eles formam configuraçôes flexíveis e repletas de tensôes." FG 311, t. 317 I.

${ }^{5}$ A exigência de integridade do direito se cumpre, antes de qualquer coisa, de forma interpretativa: "[...] é exigido de mim que encontre um lugar em toda interpretação geral de nossa prática legal para todos os princípios [...]. Nenhuma interpretaçấo geral que negasse qualquer um deles seria plausível; a integridade não poderia ser satisfeita se qualquer um deles fosse completamente rejeitado." DWORKIN, R. Law's Empire, p. 270.
}

${ }^{6} \mathrm{ED} 25$, t. 27. 
universalistas dominam - as morais convencionais não conseguem colocarse à frente delas, justamente porque há a moralização do mundo da vida: são fragilizadas ou desestruturadas as relaçôes até então institucionalmente ordenadas, com legitimidade ancorada em tradiçóes, valores culturais ou pressupostos metafísicos e religiosos.

$\mathrm{Na}$ forma reflexiva da ação comunicativa se alcançará o ponto de vista moral imparcial, posto haver a articulação das dimensôes da razão prática com base em sua incorporação na razão pública, sustentando-se a imparcialidade, com o PD, o princípio do discurso $<$ Diskursgrundsatz $>.^{7}$ Esse princípio, pela via da institucionalização jurídica, assume a forma de princípio de democracia, o qual é envolvido diretamente nas questóes de justificação das normas, e segundo o qual as normas válidas são as que, em discursos racionais, podem contar com o assentimento de todos os possíveis atingidos por elas. ${ }^{8}$

Uma norma deve pretender validez apenas quando todos os que possam ser concernidos por ela cheguem, no exercício de um discurso, a um acordo relativo a tal validez. Evidentemente, isso pressupóe a escolha fundamentada da norma, de modo que a norma válida tem que merecer o reconhecimento de todos os indivíduos, o que de antemão exclui a possibilidade de somente alguns deles poderem examiná-la. A fundamentação das normas mediante a comunicação é o meio pelo qual Habermas encontrou de reformular a teoria kantiana da moral. Na teoria do discurso, o método da argumentação moral substitui o imperativo categórico. O princípio do discurso é oriundo dessa argumentaçáo; e todo e qualquer argumento deve ser submetido a um teste de fundamentação < Begründungstest $>$.

\footnotetext{
${ }^{7}$ Sobre a imparcialidade como núcleo da razão prática, ver: FG 563, t. 214 v. II.

${ }^{8}$ FG 138, t. 142 v. I. Ver também: MkH 103, t. 116. O PD “[...] se encontra num nível de abstração que ainda é neutro em relação ao direito e à moral, pois ele refere-se a normas de ação em geral.” FG 138, t. 142 I. Sobre a transformaçáo do PD em princípio de democracia: FG 154, t. 158; 142, t. $145-146$, v. I.

${ }^{9}$ Com essa noção de teste de fundamentação, Habermas também endossa a crítica de Hegel ao formalismo kantiano. Ver: ED 24, t. 26. Para Habermas, discursos de fundamentação das normas devem ocorrer mediante a apresentação de justificações de posiçóes perante um "[...] fórum judiciário crítico", no qual se institucionalize uma "esfera pública jurídica capaz de ultrapassar a atual cultura de especialistas e suficientemente sensível para transformar as decisóes problemáticas em foco de controvérsias públicas". (FG 530, t. 183-184 v. II; ver: MkH 75, t. 86). Precisamente isso distancia Habermas, com seu PU, da proposta universalista de John Rawls sobre justiça, já que, para este, a contribuição de um participante da argumentação voltada à formação discursiva da vontade é resultado de uma teoria da justiça para a qual esse participante é competente, dada sua condição de especialista. MkH 76-77, t. 87.
} 
Mas a justificação de uma norma exige questionar como os cidadãos podem estabelecê-la dentro do Estado constitucional democrático. Isso pode acontecer segundo a linguagem moral dos direitos fundamentais, na qual o pluralismo cultural seria assegurado sob a condição de respeitar a universalidade dos direitos subjetivos e o império impessoal da lei, e, neste caso, torna-se necessária uma adaptação das particularidades contextuais à neutralidade ética dos princípios e procedimentos que o Estado democrático deve sustentar. Outra alternativa, de processamento da justificação, deve acontecer desde a consideração da vida digna, na qual a linguagem dos direitos, as práticas e instituiçóes devem expressar primeiramente os valores que formam a autocompreensão ético-cultural dos membros da comunidade política.

De acordo com o primeiro modo, se a opção for por ele, é possível violar as características e as necessidades das identidades de pessoas concretas a favor de um universalismo normativo abstrato. Da opçáo pela segunda alternativa pode decorrer uma exclusão arbitrária, com a violação dos direitos e normas universais da liberdade, possibilidade inscrita na cidadania democrática, pela práxis discursiva legitimada por pretensôes de validade dos proferimentos.

Nessa polaridade, certo é apenas que os direitos fundamentais, ao mesmo tempo em que emergem como condições extrajurídicas e juridicamente institucionalizadas que permitem a cada cidadão (enquanto indivíduo livre e igual aos demais) a conformação à lei, são também uma consequência da decisão recíproca desses cidadãos, que decidem regular suas vidas em comum por intermédio do direito positivo racional, o qual transfere para as leis o peso das normas morais que dantes, num estágio convencional, era carregado pelos próprios indivíduos. Através dos discursos racionais, todos os cidadãos participam no processo de elaboração das normas como autores do direito ao qual, posteriormente, se submetem como destinatários e deduzem direitos humanos fundamentais que são de interesse simétrico de todos. Portanto, a produção das normas deve ocorrer no interior do debate público, com a participação ativa dos cidadãos, a qual deve fornecer o substrato da adequação normativa ao Estado de direito. Por certo, trata-se de um processo complexo. Embora os direitos humanos, como princípios, indiquem que os membros do direito dão factualmente às leis uma concordância discursiva, Maus observa:

Nos domínios da ação informal, a possibilidade de contextualizaçáo de uma aplicação de normas... pode fortalecer a liberdade e a responsabilidade dos sujeitos que agem comunicativamente; porém, no interior do sistema de direito, ela significa um crescimento de poder para a justiça e uma 
ampliação do espaço de decisão judicial, que ameaça desequilibrar a estrutura de normas do Estado clássico de direito. (MAUS, 1989, p. 198).

A interpretação de Maus parece bastante coerente. Por inexistir uma plena concordância entre normatividade e racionalidade da ação orientada ao entendimento, as ideias à luz das quais o direito moderno não apenas é justificado, mas também ganha a sua própria autonomia (a saber, os direitos humanos e o princípio de soberania popular), podem encontrar na instrumentalização do sistema jurídico um bloqueador do desenvolvimento delas, tendo por consequência a insegurança destrutiva nas relaçóes de conflitos de interesses.

Destarte, como a lei tem sua gênese no poder comunicativo dos diferentes sujeitos coletivos que conformam o mundo da vida, Habermas resolve tal dilema, sustentando que o sistema de direitos, de caráter e validade universais, não define só direitos subjetivos, porém, na aplicação e interpretação que cada povo faz deles, da cultura política, mediante a qual sua cidadania os incorpora a sua validade cotidiana, a qual é expressa na ação comunicativa das comunidades. Habermas considera necessária e plausível uma atitude hipotética de uma forma de vida em face de normas e sistemas de normas e não diante de "valores culturais" entrelaçados com a totalidade do respectivo contexto de vida social. Qualquer que seja o marco institucional, o que é fundamental para ele é o fato de estabelecer "[...] uma determinada forma de integração social" que preserva a "[...] unidade de um mundo social de vida através de valores e normas". ${ }^{10}$ Nessa acepção, o próprio tribunal constitucional não paira sobre as comunidades, pelo contrário, há uma relação e ela é de dependência: somente segundo critérios estabelecidos pelas comunidades, desde que definidos democraticamente, ele deve criar e aplicar as normas legais, ou seja, elas devem ser realizadas consoantes àqueles critérios; isso a reflexão de Maus não leva em conta.

Certamente o que distingue o ponto de vista de Maus do de Habermas é o enfoque: enquanto ela prima por um diagnóstico um tanto cético em relação à realidade normativa, a análise de Habermas a respeito da produção das normas tem seu foco no processo discursivo de formação da opinião e

10 ZRhM 159, t. 125. Ver também: TkH v. II, p. 125 ss. Isso evidencia, por si só, que “[u]m paradigma jurídico nâo consegue explicar o modo como os princípios do direito e os direitos fundamentais preenchem contextualmente as funçóes que lhes são atribuídas normativamente.” FG 238, t. 241 I. Ver também: FG 54, t. 57; 163-4, t. 166-7; 244, t. 247; 286-7, t. 291 v. I. 
da vontade política; e como o direito à justificação é a "reivindicação mais geral e básica" de cada homem, isto é, o que os outros, homens ou Estados, não podem retirar, serão elas, vontade política e opinião dos cidadãos, que determinarão a justificação das normas morais e dos valores éticos. No sentido de respeito à autonomia da pessoa, o "direito à justificação" não tem uma função de intervenção na comunidade: com ele,

[...] não ficam pré-definidos quais fundamentos substanciais são adequados, quais direitos são exigidos ou quais instituiçôes ou relaçóes sociais podem ser justificadas. Como núcleo universal de cada moral interna, o direito à justificação deixa isso aos membros de contextos culturais ou sociais determinados. Se discursivamente ostentamos suas implicaçóes universalistas, esse núcleo possibilita um tipo de moral básica... (FORST, 1999, p. 79).

A ideia fundamental da teoria do discurso é que tão somente quando se obtém o consentimento racional de todos os envolvidos enquanto participantes de discursos práticos, nos quais prevalece apenas coerção do melhor argumento, é que uma norma ou valor é justificado. A justificação que acompanha toda proposta de prescrição com pretensão de validade deve ter essa validade expressa no vínculo do proferimento justificador com a exigência do cumprimento generalizado da norma. Enquanto o PD coloca os participantes numa posição de distanciamento em relação à esfera da eticidade já sedimentada, a validade normativa passa a ser examinada à luz de princípios morais, à luz do princípio de universalização <Universalizierungsgrudsatz>, o PU, segundo o qual qualquer norma válida deve satisfazer a condição dos concernidos, no que diz respeito às consequências e efeitos colaterais que resultarem do fato de ser ela universalmente seguida. De acordo com o PU,

[...] - as únicas normas que têm o direito a reclamar validação são aquelas que podem obter a anuência de todos os participantes envolvidos num discurso prático.

O imperativo categórico desce ao mesmo tempo na escala, transformandose num princípio de universalização ' $U$ ', que nos discursos práticos assume o papel de uma regra de argumentaçáo:

- no caso das normas em vigor, os resultados e as consequências secundárias, provavelmente decorrentes de um cumprimento geral dessas mesmas normas e a favor da satisfaçáo dos interesses de cada um, teráo de poder ser aceitos voluntariamente por todos. (ED 12, t. 16). 
Trata-se da obtenção de um consenso alcançado por meio procedural de deliberação acerca dos direitos humanos. No processo de autolegislação, os cidadãos atingem a validade das normas jurídicas segundo condiçôes estabelecidas pelos discursos práticos de busca cooperativa do entendimento. Obviamente, faz-se necessário encontrar os interesses universalizáveis para se estabelecer o consenso - que, por sua vez, designa um parâmetro ideal -, o que é feito no discurso, no qual todos os interessados, seguindo as pretensóes de validade (a inteligibilidade, a veracidade, a verdade, a retitude) que todo proferimento deve conter, podem levantar e criticar argumentos para, por fim, acatarem o que melhor resistir ou responder às críticas dos demais envolvidos.

Para que um acordo baseado no consenso seja possível, todos aqueles que entram no discurso, se não quiserem abrir mão de sua própria racionalidade, devem se predispor a acatar o melhor argumento. Disso advém o princípio de universalização (PU): em relação às proposiçôes normativas, as afirmações verdadeiras ou corretas não podem ser válidas para uma ou outra pessoa, pois

[a]s afirmaçóes válidas têm de poder ser defendidas com razóes que possam convencer todos em qualquer altura e em qualquer lugar. Com as suas pretensões de validade, o falante e o ouvinte transcendem os critérios provincianos de determinada comunidade particular de intérpretes, com a sua própria prática comunicativa localizada no tempo e no espaço. (ED 157, t. 154).

As pretensôes de validade, portanto, devem "transcender" todo contexto particular, porquanto ser necessário elas alcançarem uma validade universal. ${ }^{11}$ Em outras palavras, a universalidade garante a contextualidade, já que o conteúdo moral das normas se torna conteúdo jurídico. Por outro lado, as normas constituintes de uma sociedade democrática requerem sempre interpretaçôes; elas não podem ser impostas de fora e são dependentes da compreensão que cada contexto tem delas, em cada momento histórico. A

\footnotetext{
11 "A validade pretendida para enunciados e normas (também para frases que expressam vivências) transcendem, de acordo com seu sentido, os espaços e tempos, ao passo que a pretensão atual é levantada sempre aqui e agora, no interior de determinados contextos, sendo aceita ou rejeitada - o que acarreta conseqüências para a ação, gerando fatos. A validade pretendida por nossos proferimentos e pelas práticas de nossa justificativa distingue-se da validade social dos standards exercitados factualmente, das expectativas estabilizadas através da ameaça de simples açôes ou do simples costume.” (FG 36-37, t. 38-39 v. I. Ver também: LS 139, t. p. 128-129). Além disso, "[n]enhuma norma contém as regras da sua própria aplicação. As fundamentações morais não servem para nada, se a descontextualização das normas gerais, as que se recorreu para a mesma fundamentação, não poder ser compensada no processo de aplicação.” ED 24, t. 26.
} 
validade normativa baseia-se no pressuposto de que, caso seja necessário, a norma possa ser justificada e defendida contra a crítica. Certamente, isso não acontece automaticamente, trata-se da consequência de "[...] uma interpretação que admite consenso e que tem uma função justificativa”.12 A validade normativa já pressupóe que a norma possa ser justificada e defendida perante a crítica; e isso nada mais é que consequência da interpretação de uma comunidade cuja visão de mundo está voltada ao entendimento.

Um acordo tem de ser fruto de um processo cujas condiçôes devem assegurar que o conteúdo desse acordo (enquanto resultante de um entendimento dos cidadãos sobre as regras de sua convivência) expresse o ponto de vista do bem-comum e das expectativas normativas ligadas a esse bem-comum. ${ }^{13} \mathrm{O}$ acordo de uma justificação racional das normas com validade universal, para Habermas, supóe tanto o reconhecimento mútuo, como também a revisão das tradiçóes, haja vista que, politicamente, o direito de uma comunidade particular, para ser legítimo, deve estar consoante a um mínimo de princípios, os quais também presumem uma validade geral, extrapolando os valores da comunidade concreta ou de vida particular. Importa é transparecer a diferença entre a minha suposição de uma vontade geral e o acordo intersubjetivo acerca de uma vontade comum, porque

[...] enquanto cada vontade autônoma se considerar em uníssono com todos os outros habitantes inteligíveis do reino das finalidades, serão válidas as máximas que posso desejar (à luz da minha compreensão acerca do mundo e de mim próprio) como regras de uma prática geral. (ED 156, t. 153).

Todavia, como chegar a um acordo sobre os interesses de cada indivíduo, acordo esse que deve ser, concomitantemente, adequado e intersubjetivo? Para tanto, o princípio "[n]ão faças aos outros o que não queres que façam a ti” é insuficiente por permanecer preso (de forma egocêntrica) à compreensão não tematizada acerca do mundo e de nós próprios. ${ }^{14} \mathrm{~A}$ argumentação levada a

\footnotetext{
${ }^{12}$ LS 139, t. 128-129. Ver ainda: FG 162-163, t. 166 e 307-308, t. 313 v. I.

${ }^{13}$ FG 111, t. 115. Nesse aspecto, a formação da vontade é imprescindível para a fundamentação da matéria a ser regulamentada por uma comunidade; tal formação ocorre mediante questionamentos: "Quando se trata diretamente de um questionamento moralmente relevante [...] então é preciso lançar mão de discursos que submetem os interesses e orientaçóes valorativas conflitantes a um teste de generalizaçáo no quadro do sistema de direitos interpretado e configurado constitucionalmente. Ao contrário, quando se trata de um questionamento eticamente relevante [...] entáo é o caso de se pensar em discursos de auto-entendimento, que passam pelos interesses e orientaçóes valorativas conflitantes, e numa forma de vida comum que traz reflexivamente à consciência concordâncias mais profundas." FG 204, t. 206-7 v. I.
}

${ }^{14} \mathrm{ED} 156$, t.153. 
efeito intersubjetivamente conduz os participantes a uma ampliação idealizante de suas perspectivas interpretativas, de forma a superar o provincianismo e interesses próprios. Mediante os pressupostos gerais da comunicação relativos à prática argumentativa, o alargamento das perspectivas hermenêuticas é possível e necessário.

Nesse ponto, Habermas recorre à noção peirceana de comunidade hermenêutica <Interpretationsgemeinschaft $>$. Nas pretensôes de validade se pode perceber um sentido de transcendência: para se obter o sentido de verdade de um proferimento, é preciso recorrer à referência contrafactual do cumprimento de validade sujeita à crítica, bem como atender às "[...] condiçóes comunicativas de uma comunidade hermenêutica alargada, em termos ideais, a um espaço social e a um tempo histórico". ${ }^{15}$ Os desacertos de qualquer conjunto de normas legais não se esgotam nas suas impossibilidades de execução. Inaplicabilidade de uma norma em geral não é de ordem material, mas axiológica, daí a necessidade da comunidade hermenêutica, da interpretação dos princípios: o acordo a que se chega náo é o de que a norma seja ou náo possível de aplicação, mas sobre a própria aplicação, se ela é ou não indispensável ou inconveniente. Em outras palavras, o quanto um ordenamento legal é democrático depende diretamente de uma concretização que deve se realizar, por meio de uma práxis hermenêutica predominante no contexto relativo a tal ordenamento:

O mundo como o conjunto dos fatos possíveis constitui-se para uma comunidade hermenêutica, cujos membros chegam a acordos sobre as coisas do mundo, no quadro de um contexto prático partilhado intersubjetivamente. Considera-se "real" aquilo que pode ser formulado em afirmaçóes verdadeiras, significando "verdadeiro", por sua vez, aquilo que se pode explicar em referência à pretensão feita pelo indivíduo em relação a outros quando aquele faz afirmaçóes. $\mathrm{O}$ sentido assertórico da afirmação feita pelo falante levanta uma pretensão sujeita à crítica quanto à validade da asserçáo proferida; e como ninguém tem acesso direto a condiçóes de validade não interpretadas, a "validade" tem de ser entendida epistemologicamente como "o valor estabelecido para nós". Toda a pretensão justificada de verdade da parte de um proponente tem de poder ser defendida com base em razóes, contra as objeçôes de eventuais oponentes e tem de poder contar, em última análise, com um acordo de

${ }^{15}$ ED 159, t. 155. Na moral dessa comunidade hermenêutica, e não em si mesma, é que se encontra fundamentada a noção de justiça: a competência linguística dos sujeitos autolegisladores é necessária para eles poderem diferenciar entre vida boa e vida correta, posto as diferenças entre ambas não serem "[...] meras preferências, sobre as quais se encontram coisas legítimas dos concernidos, mas sim as que em sentido estrito são capazes de verdade”. FG 190, t. 193. 
motivação racional por parte da comunidade hermenêutica como um todo. (ED 158, t. 154).

Os pressupostos comunicativos de todos os componentes de um discurso assumido por uma comunidade hermenêutica podem ser apenas aproximadamente realizáveis "[...] sempre que afirmem ou contestem a verdade de uma asserção ou que entrem numa argumentação, a fim de justificarem determinada pretensão de validade." 16 A verdade a que tal comunidade chega mediante discurso é essencial para a sustentação da universalidade das suas regras normativas, que devem estar fundamentadas no discurso moral. Por conseguinte, o que é factível não pode eliminar o contrafactual. $\mathrm{O}$ ponto que parece ser central aqui é entender corretamente a incondicionalidade das pretensôes de validade pertinentes tanto aos discursos de aplicação, quanto aos de fundamentação. A razão prática ampara a perspectiva argumentativa; em qualquer comunidade jurídica, ela se desloca do âmbito da eticidade rumo ao âmbito das regras discursivas, e retira daí seu teor normativo, o qual sustenta a validade de um acordo mútuo. Pela perspectiva argumentativa, ao se chegar ao acordo consensual, princípios básicos deverão embasar opinióes qualificadas a respeito de medidas garantidoras da implementação dos direitos humanos. Um pressuposto "incondicional” é imprescindível nisso, haja vista que, para as pretensóes transcendentes de validade se tornarem realizáveis no mundo, há necessidade de condiçôes cujo cumprimento satisfatório constitui tal pressuposto, a saber, a possibilidade de uma fundamentação universal, a qual funciona normativamente para avaliação de argumentaçóes morais ou jurídicas. Este é um pressuposto normativo contrafático que pode não corresponder à realidade sem, contudo, deixar de ser válido.

Os pressupostos, que devem assegurar às pretensóes de validade o caráter de incondicionalidade, são pressupostos contrafáticos do agir comunicativo e, quando considerados, nâo o são sem problemas, dentre os quais está a "face de Jano" <Janusgesicht> inerente às pretensóes de validade de qualquer argumentação. ${ }^{17}$ A teoria do discurso pretende explicar como os direitos humanos salvaguardam o momento ideal de incondicionalidade, que

${ }^{16}$ ED 158, t. 154; também: 42, t. 38.

${ }^{17}$ Tais pretensôes são, pois, validade última de um discurso argumentativo, mas com elas sustenta-se também "[...] a consciência de que as razôes que hoje convencem suficientemente poderiam sucumbir à crítica amanhâ". Habermas, "Entgegnung”, p. 351. Ver ainda FG 36-37, t. 38-39 v. I. A constituição da realidade social, com isso, é determinada por esse "nivel de idealização", de "[...] tal modo que todo acordo obtido comunicativamente e que torna possível a coordenação de açôes, bem como a 
[...] está enraizado nos processos de entendimento factuais, porque as pretensóes de validade póem à mostra a dupla face de Jano: enquanto pretensóes, elas ultrapassam qualquer contexto; no entanto, elas têm que ser colocadas e aceitas aqui e agora, caso contrário não poderão ser portadoras de um acordo capaz de coordenar a ação... (FG 36-37, t. 38-39 v. I).

Como a aplicação de normas jurídicas institucionalizadas a partir de acordos consensuais procede de forma abstrata e geral, os motivos contextualmente específicos e/ou individuais não podem ser levados em conta. Com isso, admite Habermas, as instituiçóes adquirem um certo caráter ambivalente, na medida em que os interesses só podem ser satisfeitos a longo prazo sobre a base de expectativas generalizadas de conduta e quando ligados a ideias justificadoras de pretensóes de validade normativa. Daí a justificação racional das normas de ação e de avaliação morais ser um problema axial. Donde também as condiçóes de possibilidade de justificação racional das normas (de ação, de avaliação) serem condiçôes que tanto possuem um caráter normativo, pragmático, quanto universal.

As pretensóes próprias das formas de vida particulares não podem extrair seu valor para o indivíduo de uma universalização abstrata. Apenas a interpretação da comunidade (a comunidade hermenêutica da qual fala Habermas) pode atuar previamente ao desenvolvimento dos discursos efetivos e chegar a garantir a elucidação racional de questóes morais, para que as normas em concreto possam vincular moralmente as condutas, sem negar o que é bom para a comunidade. A sustentação da norma que traduz o que é correto universalmente, consoante ao bem para a comunidade, náo prescinde da noção de situação ideal de fala como parâmetro regulador, por meio da qual são aceitos princípios procedimentais com significação ética (dentre os quais: autenticidade e simetria da participação, exclusão de toda coação exceto a do melhor argumento etc.). Isso porque, para Habermas, é necessário refletir sobre a perspectiva normativa e, com isso, procurar fundamentar a superioridade do modo reflexivo de justificação, o que é feito pela abordagem

estrutura complexa de interações e a interligação de seqüências de açóes, mede-se pelo reconhecimento intersubjetivo de pretensóes criticáveis..." (FG 36-37, t. 38-39 v. I). Nesse contexto, o uso ético-político da razão prática deve constituir os discursos de fundamentação e de aplicação das normas. (FG 191, t. 194 I). A "face de Jano" também é considerada, no que concerne aos direitos humanos em alguns textos de Habermas, tal como Direito e democracia (tópico três do terceiro capítulo), A inclusão do outro (capítulo sete), e ainda em Sobre a constituição da Europa, (tópico I do primeiro capítulo), mas como não estamos tratando aqui especificamente da teoria habermasiana dos direitos humanos, não adentraremos nessa característica deles. 
pragmática de uma teoria da argumentação em geral da qual emerge o princípio de universalização como regra argumentativa no discurso prático.

Mormente todo proferimento deva ser avaliado e as pretensóes de validade possam ser pensadas como universais, no sentido de válidas para toda a humanidade, o que é um acontecimento histórico, a questâo aqui a ser colocada é: esse acontecimento histórico manifesta uma tendência interna dedutível do funcionamento do discurso, mas visível somente a posteriori, ou é um acontecimento histórico contingente específico de uma sociedade? Somado a isso, se levarmos em conta a "face de Jano" das normas, surge também a questão: o programa habermasiano não é eminentemente normativo e desse programa não pode decorrer uma restrição da moral expressa na normatividade das leis? Como será visto adiante, procuraremos respostas a essas questóes, mas a esta última, por duas razóes, que são interdependentes, a negação parece evidente: primeiro, nesse programa, a normatividade recebe um enfoque vinculado à razão prática, mediante a categoria de reciprocidade; segundo, porque nele essa categoria recebeu um fundamento psicossocial.

\section{II - DA RECIPROCIDADE}

$\mathrm{Na}$ teoria do discurso há, de forma nem sempre muito explícita, um modelo de legitimidade da lei que obedece à realização dos direitos universais na expressão de autoentendimento particular de cada sujeito e nas formas de vida das comunidades: os participantes de uma situação de fala não têm alternativa se nâo outorgarem-se reciprocamente os direitos fundamentais da pessoa humana. Esse modelo refere-se normativamente ao padrão organizacional da reciprocidade, por apontar a uma ordem social de valores, na qual as finalidades sociais passam por uma rica e complexa interpretação.

Sujeitos responsáveis, sujeitos detentores de competência interativa, que orientam suas açôes por pretensôes de validade tratadas como hipóteses que traduzem uma espécie de ação comunicativa tornada reflexiva, mantêm o reconhecimento recíproco e, com base nele, os princípios como a igualdade de tratamento, a solidariedade. Sáo esses sujeitos que apresentam tanto o interesse em poder participar na produção do "consenso" sobre a verdade acerca de enunciados relativos à validade de uma norma jurídica, quanto um interesse formal convergente, que deve preponderar sobre interesses divergentes possíveis de existir entre eles. O dever de cada membro de uma comunidade de reconhecer os interesses dos demais é concomitante ao seu direito de fazer 
valer, em situações específicas, os seus interesses, portanto, este não impede a comunidade de atingir um juízo imparcial a propósito do interesse comum.

O êxito das orientações universalistas direcionadas ao entendimento $<$ Verständigung>, um norteador dos discursos, contudo, não advém da própria comunidade hermenêutica, mas da racionalidade comunicativa. Isso suscita o questionamento a respeito das normas morais e legais, reguladoras da coexistência desses sujeitos: elas não levam a um patamar final, já que são compartilhadas intersubjetivamente? Por que, ao permitirem a organização de sistemas de ação, elas não estagnam as açóes em normas estabelecidas definitivamente e, portanto, em direitos humanos também não carentes de interpretaçôes e reformulaçôes, mas contribuem, de fato,para a formação de novos níveis de interação social?

As consideraçóes evolucionistas de Habermas podem oferecer respostas a tais questôes. Quando numa fase convencional, de identidades de papéis, a interação social é guiada pelo dever em obedecer a normas, a consciência moral apresenta-se no estágio sociocêntrico-objetivista. Aqui, a aplicação prédeterminada de normas, sem o processo de discussão seguido de acordo, indica um sistema convencional, no qual a moral do sistema social constitui o pano de fundo de legitimação inclusivo, originalmente fundido com a adequação e comumente apoiado institucionalmente por autoridades, de sorte que o "sistema" de normas aparece como se a sua validade fosse adequada de modo hierárquico pré-determinado e naturalmente. Destarte, a análise da definição prévia das necessidades e dos direitos individuais não consta na obra de Habermas. Para o caso de direitos pré-estabelecidos, o que conta é o processo de aquisição da linguagem comum pelo indivíduo, o qual é, sobretudo, o processo de adaptação do indivíduo a um consenso pré-estabelecido que, por sua vez, é consequência, em cada momento, de um desenvolvimento histórico da linguagem. Esse consenso é, ao mesmo tempo, um consenso acerca da aceitação de normas. Não há como exercitar a linguagem sem estar, direta ou indiretamente, referindo-se às normas, mesmo sendo préestabelecidas, e possivelmente carentes de revisão. Isso nada mais indica que uma institucionalização legal do PD exige seu reconhecimento como direito natural à livre comunicação, por isso, no modelo habermasiano, tal princípio é anterior aos direitos humanos e tão-somente com o reconhecimento ab ovo dele se pode alcançar uma normatividade legítima.

Desse estágio decorre, passo a passo, o avanço para a intersubjetividade, um nível tal em que o eu então não apresenta sua ação conforme a norma legal 
ou moral, ele se descentra de si, e como sujeito de direito busca, em vez das normas grupais, os princípios universalizantes, posto agora ele poder distinguir entre normas e princípios segundo os quais são produzidas as normas.

Para o indivíduo chegar a ter consciência de si como sujeito de direito, o processo de formação é construído na forma de uma sequência de passos da realização da vontade individual: com essa formação, a vontade individual pode se conceber como uma pessoa dotada de direitos, ela está capacitada a participar naquela esfera contextual em cujo quadro se realiza a reproduçáo da vida social. A aprovação de normas, o consentimento, Habermas vincula a um processo de formação da vontade pública, que deve abarcar as condiçóes necessárias da autoexperiência da consciência individual: um sujeito precisa passar por experiências, repletas de exigências, antes de estar em condiçóes de conceber a si mesmo como uma pessoa dotada de "direitos", como sujeito de direito. Aquele que não se submete à norma deve experienciar o constrangimento jurídico, do que pode ser entendido que a "vontade singular" fica então sem reconhecimento recíproco. A medida mínima de concordância comunicativa, de "vontade geral", que permite uma reprodução comum das instituiçóes, é dada numa sociedade apenas com a instituição do sujeito de direito, o qual entáo pode participar na vida regulada da sociedade: uma autoexperiência integral do sujeito, como seria dada com a consciência dos direitos, é possível unicamente sob a condição de que o indivíduo aprenda a conceber-se também como um eu pós-convencional.

A autocompreensão desses eus, sujeitos de direito, pós-convencionais, pressupóe que eles se concebam como seres intersubjetivos - o processo de formação da vontade requer a ampliação da própria compreensão que têm de si e abarca uma dimensão complementar da relação prática com o mundo. Essa compreensão que cada um tem de si, mesmo como portador de direitos somente quando possui um saber sobre quais obrigaçóes tem de observar em face do outro, ${ }^{18}$ e isso apenas da perspectiva de um "outro generalizado" (tomo aqui a expressáo de Mead), já ensina a cada qual a reconhecer os outros membros de sua comunidade linguística.

18 "Quem, em nome do universalismo, exclui o Outro, que tem o direito a permanecer um estranho em relação aos outros, atraiçoa os seus próprios princípios.” ED 116, t. 115. Se o discurso prático-moral é dissociado de propósitos de sucesso e individualistas é porque nele está pressuposto o "Outro" como aquele que se „depara com a razáo verificadora de normas, enquanto oponente numa argumentação imaginária, porque alargada de forma contrafactual... ”. ED 116, t. 115. 
Essa identidade pós-convencional, por sua vez, está inserida numa identidade coletiva que evolui no sentido da interação linguística e, com isso, ou em decorrência disso, participa da elaboração das normas. Consoante a tal modelo, a reciprocidade, concebida na etapa da vontade/assentimento geral como uma força motriz do processo de formação da vontade púbica, produz exigências modais para as quais nós mesmos náo sabemos indicar formas adequadas de resolução jurídica; trata-se de resoluçóes não pré-dadas, o próprio desenvolvimento dessas resoluçóes deve ser atribuído à pressão normativa da reciprocidade.

Esse processo interativo, baseado na consciência de ter oportunidades iguais e racionais na formulação das normas, tem a ver com o próprio processo de aprendizagem que possibilita aos concernidos resgatar de modo crítico e reflexivo os valores da tradição. Como participantes iguais em discursos racionais, esses sujeitos têm de examinar se a norma em questão pode obter o assentimento de todos os possíveis afetados, capacidade de exame na qual já estão pressupostas relaçôes de reciprocidade em que a igualdade legal está associada à participação no discurso. Contudo, Habermas alerta: somente poderão se encontrar unidos em torno desse ponto de vista capaz de efetivar o consenso, se ele resultar das estruturas de interação, independentemente de terem ou não em comum a origem social, a tradição etc. Nas estruturas de interação pressupóe-se a reciprocidade entre os sujeitos agentes.

Reciprocidade não é norma ou ditame; por estar presente nas estruturas de interação, ela faz parte do saber intuitivo de sujeitos capazes de linguagem ou de ação: ${ }^{19}$ os pressupostos comunicativos, sob os quais participantes de um discurso realizam seus acordos "[...] esclarecem um ponto de vista moral que não é privilégio de uma determinada cultura, uma vez que está ancorado mais profundamente e em último sentido, nas simetrias do reconhecimento recíproco em geral de sujeitos que agem comunicativamente." ${ }^{20}$

\footnotetext{
${ }^{19}$ ZRhM 82, t. 67. A noção de reciprocidade de Habermas segue o raciocínio de Hegel, segundo o qual os conflitos precisam ser solucionados mediante discussão racional. Os conflitos fluem da linguagem cotidiana por intermédio dos agentes comunicativos: "Os conteúdos avaliados à luz de um princípio moral são, entấo, gerados, não pelos filósofos, mas sim pela vida. Os conflitos de conduta, que devem ser avaliados moralmente e solucionados por consenso, emergem da prática comunicativa cotidiana, sendo encontrados - e não produzidos - pela razão avaliadora de máximas ou pelos participantes da argumentação." ED 21, t. 24.

${ }^{20} \mathrm{FG} 86$, t. 90 . E " $[\mathrm{t}]$ odas as morais se movimentam em torno dos princípios relativos à igualdade de tratamento, à solidariedade e ao bem-estar geral; estas são, todavia, noçóes fundamentais que se reportam às condiçōes de simetria e às expectativas de reciprocidade da ação comunicativa" ED 17 , t. 20. Ver também: ZRhM, 80, t. 64.
} 
O conceito de reciprocidade designa, sobretudo, a relação entre indivíduos que se respeitam mutuamente como sujeitos de direito. Sujeitos pós-convencionais, conhecem as normas sociais por meio das quais os direitos e deveres são legitimamente distribuídos nas suas respectivas comunidades e, neles, com isso, o respeito mútuo é um corolário da reciprocidade. Os eus pósconvencionais são autolegisladores, são os eus descentralizados, cuja alteridade os potencializa ao consenso e à reciprocidade, são os "eus" autores dos direitos humanos, capazes de autodeterminaçáo e competentes para apropriarem-se ou (criarem) normas que possibilitam a regulamentação de outras normas, de um processo de desenvolvimento que envolve etapas, estágios, os quais se caracterizam pela passagem da menor à maior apropriação de sua história. Conforme o entendimento de Habermas, nas relaçóes recíprocas existentes entre pessoas capazes de orientar suas açóes por pretensóes de validade se encontram "[...] instaladas as ideias de justiça e de solidariedade"21; esta, enquanto princípio sustentador da "imanação num universo comum", é um instrumento de integração social mediante o qual ocorre a intervenção das forças sociais tendentes a garantir os direitos humanos e não permite a intervenção no mundo da vida de sistemas como mercado e administração.

A reciprocidade não prescinde da norma legal, pois o direito moderno representa um medium de reconhecimento que expressa propriedades universais de sujeitos humanos de maneira diferenciada, mas também não prescinde da forma de vida. Bem comum, respeito igual, solidariedade são ideias básicas de qualquer moral presente nas formas de vida concretas. Elas são levadas em conta pelo discurso prático, e nele derivarão das condiçóes de simetria e das expectativas de reciprocidade características da ação comunicativa. A forma de reconhecimento de estima social requer um medium social que deve expressar as diferenças de propriedades entre sujeitos humanos de forma universal, isto é, intersubjetivamente vinculante.

Habermas, com base em seus estudos de psicologia social e cognitiva, localizou na lógica do desenvolvimento a presença da reciprocidade em três níveis (pré-convencional, convencional e pós-convencional) e também uma indicação precisa da forma de reconhecimento recíproco. Todavia, conceber a

${ }^{21}$ ED 155, t. 152. Sobre a relaçâo entre reciprocidade e respeito, ver: ED 148, t. 146. E sobre a capacidade de entendimento recíproco dos participantes de processos interativos como contraponto ao risco de dissensão oriundo da raconalizaçáo do mundo da vida, ver também: PDM 404-405, t. 484-485. 
reciprocidade como pedra central da construção de normas requer considerála nos estágios 5 e 6 do nível pós-convencional, ${ }^{22}$ nos quais ela é completa.

Nesses estágios, princípios transformados em temas morais acabam, por exigências lógicas, postulando uma reciprocidade completa <vollständiger Reziprozität $>$ e, desde essa perspectiva, migra para a relação de reconhecimento uma nova forma de reciprocidade, altamente exigente: obedecendo à mesma lei, os sujeitos se reconhecem reciprocamente como pessoas capazes de decidir com autonomia individual sobre normas morais que afetam suas vidas concretas. Isso explica, segundo a lógica do desenvolvimento, por que a participação na elaboração das leis pode ocorrer tão-somente com relação à condição de sujeitos de direito <Rechtssubjekte>, os quais, como portadores de direitos, pertencem voluntariamente a uma "associação de companheiros jurídicos" $<$ Rechtsgenossen $>$, propriedade jurídica garantidora do cerne normativo da sua existência e não propriamente das normas: "[...] somente podem pretender validade legítima as leis jurídicas capazes de encontrar o assentimento de todos os parceiros do direito, num processo jurídico de normatização discursiva”. ${ }^{23}$

Certamente tal associação de companheiros jurídicos implica uma comunidade hermenêutica cujo êxito irrestrito no seu processo de interação normativa pode ser obtido unicamente na medida em que lhe correspondem, pelo lado dos seus membros, hábitos culturais que têm a ver com a forma de seu relacionamento recíproco. Nesse processo operado, no nível social, por um quadro de orientaçóes simbolicamente articulado, mas sempre aberto e poroso, são formulados os valores e objetivos éticos, cujo todo constitui

\footnotetext{
${ }^{22}$ No primeiro estágio do nível pré-convencional, devido a serem consideradas moralmente relevantes ações concretas e suas consequências específicas, em termos de sançôes ou gratificaçốes, há uma reciprocidade incompleta - "[...] uma pessoa pode esperar ou fazer x e a outra pode esperar ou fazer y (p. ex.: professor/aluno; pais/filhos)" - porque a criança se encontra numa posiçáo de desigualdade perante os que lhe prometem gratificação ou punição em dependência da sua ação, que é realizada segundo um modelo de orientação "obediência-punição". No segundo estágio desse nível, há uma reciprocidade completa - posto haver uma relação completamente recíproca quando ambas as pessoas "[...] podem fazer ou esperar a mesma coisa $(\mathrm{X}=\mathrm{Y})$ (p. ex., as normas do direito privado)" - a criança, movendo-se pela orientação do hedonismo instrumental, não pode se furtar à consciência de que as demais crianças também ajam, em função de interesses privados, o que as coloca em pé de igualdade. No nível convencional, no terceiro estágio, temos que a reciprocidade volta a ser incompleta, pois a orientação do "bom moço" mantém exigências de reciprocidade para com pessoas de referência. No quarto estágio, a reciprocidade é incompleta - a mesma exigência se verifica em relação aos sistemas de normas. ZRhM 82-84, t. 67-69.
}

${ }^{23}$ FG 141, t. 145 v. I. Ver também: PK 176, t. 148-149. Na sua respectiva comunidade jurídica, “[...] ninguém é livre enquanto a sua liberdade implicar a opressão de outro. Pois a distribuição simétrica dos direitos resulta do reconhecimento de todos como membros livres e iguais. Esse aspecto do respeito igual alimenta a pretensão dos sujeitos a iguais direitos.” FG 504-5, t. 159 II. 
a autocompreensão cultural dessa comunidade. Critérios pelos quais é orientada a reciprocidade entre as pessoas, são predeterminados por essa autocompreensão cultural, já que as capacidades e realizaçôes dessas pessoas são julgadas intersubjetivamente, sempre conforme a cooperação delas na implementação de valores e normas também culturalmente definidos. Nesse sentido, essa forma de reconhecimento recíproco está ligada à pressuposição de um contexto de vida social cujos membros constituem uma comunidade de valores mediante a orientação por concepçóes de objetivos comuns.

Desde essa perspectiva, os conceitos fundamentais, com que são circunscritas as pressuposiçôes de existência de formação de tal comunidade, devem ser talhados para as propriedades normativas das relaçóes comunicativas. Esse modelo normativamente refere-se ao padrão organizacional da reciprocidade: o reconhecimento recíproco requer um medium social que deve expressar as diferenças de propriedades entre sujeitos humanos de maneira universal, isto é, intersubjetivamente. A potencialização das instâncias comunicativas nos diversos planos do mundo da vida permite que as identidades pós-convencionais consigam contaminar gradual e difusamente os sistemas normativos, de forma a indicar um pressuposto universalista, mesmo quando parecer que se discute problema circunstanciado.

Desse modo, a identidade pós-convencional coletiva, indo além da identidade coletiva particularista e não resvalando para um "universalismo a-ético de mercado", passa a ser fundada "[...] na consciência de ter oportunidades iguais e gerais para participar em processos de aprendizagem criadores de normas e valores". ${ }^{24}$ Para tanto, é necessária a mesma conjunção de competências exigidas da identidade individual, a saber, reciprocidade, reconhecimento e consciência de oportunidades iguais e gerais de participaçáo para todos, em um contexto em que, mesmo enfrentando as solicitaçóes próprias a cada identidade individual, presentemente, todas elas se colocam o objetivo futuro de um consenso que as reúna - é o agir comunicativamente fundado em vistas de uma sociedade justa.

A estrutura da qual Habermas pode derivar suas determinaçóes da identidade ou eu pós-convencional só assume a forma de reconhecimento recíproco quando ela se torna dependente historicamente das premissas dos princípios morais universais. Donde a capacidade genuinamente moral de um sujeito não poder ser considerada característica antropológica universal

${ }^{24} \mathrm{ZRhM} 117$, t. 100. E isso, mesmo que resgatando criticamente os valores da tradição. 
e abstrata, mas unicamente histórica - e histórica, não num sentido de uma pertença a uma cultura particular, mas no sentido forte de um acontecimento ligado a um desenvolvimento lógico, à realização das potencialidades contidas no discurso livre. Os principais conceitos sociocognitivos da interação guiada por normas <normengeleiteten Interaktion $>$ se formam táo somente no quadro de uma compreensão descentrada do mundo que se deve à diferenciaçáo das perspectivas do falante e do mundo, e as quais se ajustam à lógica do desenvolvimento, baseada nos estágios dos juízos morais de Kohlberg, em que o papel da reciprocidade se registra. Para a existência concreta da possibilidade de "uma lógica do desenvolvimento", porém, com base no direito fundamental, se requer "[...] sempre outras fundamentaçóes para as relaçóes sociais e podem ser propostas outras justificaçôes construtivas de direitos". ${ }^{25}$

Uma pluralidade de ideais de vida, que envolvem convicçóes axiológicas contrapostas em geral, constitui a realidade na qual deve ocorrer a aplicação de uma norma. Isso exige não deixar de levar em conta o agudo problema de como um ordenamento jurídico-legítimo pode surgir no robusto seio das sociedades modernas altamente complexas, cuja trama de relaçóes dificulta em muito tal posição. Daí não ser possível sustentar um desligamento entre a lógica do desenvolvimento moral e o âmbito jurídico: a aplicação das normas, ao assumir a forma jurídica, constitui um processo no qual estáo em jogo questionamentos políticos de várias espécies. Se isso, por um lado, deixa visível a distinção entre o contexto de fundamentação e o contexto de aceitação da norma, por outro, denota que o enfoque sociopsicológico da reciprocidade não prescinde do papel da juridicização delas.

\section{III - CONSIDERAÇÓES FINAIS}

A prioridade dos direitos humanos, de um prisma da lógica do desenvolvimento, está vinculada à questão da obediência e da reciprocidade: uma disposição para a obediência a normas jurídicas somente pode ser esperada dos parceiros de interação, quando eles puderem assentir a elas, em princípio, como seres livres e iguais num contexto comum. Sobre esse contexto, os parceiros de uma situação de fala, embora culturalmente muito distantes uns dos outros, podem se corrigir reciprocamente e desenvolver uma interpretação comum dos direitos humanos, constituindo uma identidade coletiva, como

${ }^{25}$ FORST, R. Das grundlegende Recht auf Rechtfertigung, p. 78. Ver também: MkH 151, t. 172; 143, t. 163. 
resultante de normatizaçôes. Porém, tal processo aponta para a emergência, ainda que embrionária, de contextos ou sociedades de nível pós-convencional, nos quais predominarão os eus pós-convencionais: os sujeitos que vivem em um determinado mundo da vida descobrem que eles já se reconheceram previamente em seus direitos fundamentais. Isso, todavia, não permite inferir que, em Habermas, prepondera uma acepção moral de direitos humanos.

Em contextos em que inexistem formas de vida compartilhadas por todos que possam garantir, a partir de acordos fundados na reciprocidade, a força motivacional para a obediência a normas, o direito em geral ocupa o espaço de normatizador. Para esses contextos, os direitos humanos serão préestabelecidos, mesmo que por vezes isso implique certa coerção, pois o "[...] o código jurídico já deve encontrar-se como tal à disposição antes de que os pressupostos comunicativos para uma formação da vontade discursiva possam ser institucionalizados na figura dos direitos civis." ${ }^{26} \mathrm{E}$, mesmo assim, os direitos humanos não podem ser impingidos de fora, como restrição, porque eles institucionalizam as condiçóes de comunicação para a posterior formação da vontade racional. Isso, porém, é mediato apenas para os direitos políticos civis, isto é, para os direitos à comunicação e à participação. Para os direitos que garantem a autonomia privada dos cidadãos, os direitos clássicos à liberdade, não é evidente essa não imposição "de fora", por tais direitos possuírem um valor "intrínseco" <intrinsischen Wert> - que se revela tanto quando devem garantir chances iguais a todos, quanto quando devem assegurar a todos a devida e abrangente proteção jurídica. Aos eus convencionais, eus centrados em si mesmos, as obrigaçóes normativas adquiridas mediante formas simples de interação social não apontam para além dos limites de um universo concreto, seja ele familiar, social, seja relativo à nacionalidade.

Habermas não alude a como pensar o pré-estabelecimento dos direitos humanos, mas trata do comportamento sob o imperativo das pretensóes de validade dos proferimentos argumentativos como o sinal distintivo da racionalidade, a qual deve ser compreendida como a qualidade típica daqueles que podem entreter uma forma de vida caracterizada pela situação de fala ideal, antecipada como condiçáo constitutiva do discurso possível - junto à maneira particular segundo a qual deve ser efetuada a reciprocidade intersubjetiva da unicidade biográfica de todos os sujeitos.

${ }^{26}$ PK 176, t. 148. Ver também: NU 86; EA 300, t. 292. 
Não há indicaçôes precisas sobre os direitos que cabem a cada um individualmente e nem sobre o modo por força do qual eles são engendrados no interior das comunidades - os discursos de fundamentação das normas constituem um postulado ideal. Antes, visa-se tão somente à condição elementar de que todo sujeito humano possa ser considerado portador de alguns direitos, quando reconhecido socialmente como membro de uma coletividade: do papel socialmente aceito de membro de uma comunidade resultam determinados direitos para o indivíduo, cuja observação ele pode reclamar em casos normais, apelando a um poder de sanção dotado de autoridade. Esse é um conceito de ordem social apropriado para caracterizar as propriedades gerais que competem ao reconhecimento jurídico em sociedades convencionais: enquanto as pretensôes legítimas do indivíduo não são ainda carregadas com os princípios universalistas de uma moral pós-convencional, elas se constituem em princípio apenas de atribuições que lhe cabem em virtude de seu status de membro de uma coletividade concreta.

Em sociedades nas quais os sujeitos de direito não participam na elaboração dos direitos humanos, eles ao menos devem poder contemplar seus pontos normativos comuns na forma objetivada da lei; esta representa, por sua vez, a quintessência de todas as prescrições mediante as quais as relaçóes jurídicas entre os sujeitos são formalmente reguladas. Torna-se pertinente, entrementes, admitir: no ponto de interseção do sujeito jurídico reconhecido, no qual os processos de formação individual de cada membro de uma comunidade acabam coincidindo, Habermas deixa em aberto até que ponto esses sujeitos devem se reconhecer reciprocamente e como esse processo adquire força efetiva na normatização assegurada historicamente pelo Estado. Se isso fica em aberto, entâo é necessário reconhecer que a análise de Habermas começa interpretando a todo custo o ato da participaçáo discursiva como uma exigência radical de reciprocidade para, em seguida, não poder mais integrá-la no próprio quadro da relação jurídica. Como somente no plano institucional da relação jurídica é que as normas assumem o caráter de prescriçóes legais publicamente controladas, resulta, por conseguinte, que elas não são concretizadas ou diferenciadas mais além do poder de sanção do Estado.

Esse limite subsiste às argumentaçóes habermasianas porque, ao que parece, no concernente à temática deste texto, se entrecruzam um modelo ideal postulado pela teoria do discurso (com PU, PD e pretensóes de validade) - o qual serviu de escopo à análise aqui desenvolvida - com consideraçóes acerca do diagnóstico de época. Conforme o modelo ideal habermasiano, é no interior 
do debate público, com a participação efetiva dos cidadáos, que deve ocorrer a interpretação e a produção das normas. Entrementes, numa perspectiva de diagnóstico de época, Habermas expõe uma visão, cujo realismo não comporta encanto algum: ele não só admite que "[...] hoje como ontem persiste uma grande discrepância entre a letra e o cumprimento das normas", ${ }^{27}$ como também que, devido à "indeterminação cognitiva” de cada cidadão comum (já que a capacidade analítica dessas pessoas, enquanto cidadãos não detentores da linguagem do direito, fica sobrecarregada com "problemas de fundamentação e de aplicação de questôes complexas"), concretamente é retirada das pessoas jurídicas, enquanto destinatários dos direitos, a possibilidade de definir critérios de julgamento acerca do justo ou injusto. Retirar tal possibilidade de participar na definição desses critérios, porém, desde essa perspectiva, tanto não deixa de ser um alívio para os cidadãos comuns, por não sobrecarregá-los com "[...] o peso cognitivo da formação do juízo moral próprio"28, como, em concomitância, não fere a autonomia pública, porquanto o legislador náo pode decidir nada que desrespeite os direitos humanos. Isso parece indicar que, nessa dualidade de entendimento, ${ }^{29}$ um idealizador e outro voltado às condiçóes objetivas das sociedades capitalistas, a identificação entre legitimidade dos direitos humanos e direitos humanos produzidos democraticamente, ao menos em se tratando de contextos convencionais, exige necessariamente repensar PD na produção desses direitos, para não se cair num formalismo criticado pelo próprio Habermas. ${ }^{30}$

Em decorrência mesmo daquele referido entrecruzamento, ao perscrutar resposta a nossa questão central (sobre o status das normas e sua forma de instituiçãa), processou-se no curso deste texto um deslocamento para outra, a saber, a questão sobre o quanto o modo de sustentação da normatividade jurídica de um ordenamento social o determina como democrático ou não. Este também ficou sem resposta, já que o modelo ideal da teoria do discurso não chega às possibilidades empíricas de implementação das normas como direitos humanos - e recorrer a uma outra análise de Habermas, às consideraçóes sociopolíticas, seria infrutífero para o propósito aqui, visto que não se pretende tratar de diagnóstico de época.

${ }^{27}$ EA 213, t. 206.

${ }^{28}$ FG 147 , t. 151 v. I.

29 Para não fazer referência a duas perspectivas metodológicas distintas (KNEER, 1990), visto esse tema fugir ao propósito de análise deste texto.

${ }^{30}$ FG 551, t. 202 v. II: "Somos levados a falácias concretistas, quando pretendemos amarrar o formalismo do direito em geral a propriedades de determinado modelo histórico..." 
Em Habermas, encontramos aquilo que Hegel já havia compreendido, isto é, que o direito representa uma forma de reconhecimento recíproco por meio do qual cada pessoa experiencia, como portador das mesmas pretensões, o mesmo respeito. Isso pode ser estendido para os direitos humanos. Como portadores de direitos, a autocompreensão dos sujeitos de direito dá-se no sentido de que podem estar seguros do cumprimento social de algumas de suas pretensóes. No entanto, como o conceito de "outro generalizado", que serve de base à categoria de reciprocidade, refere-se muito pouco a uma ordem elementar de direitos e deveres cooperativos, com base no modelo habermasiano, pode-se atribuir ao reconhecimento jurídico somente um reduzido conteúdo normativo: o que no sujeito individual alcança aqui reconhecimento de maneira intersubjetiva é sua qualidade legítima de membro de uma comunidade. A identidade coletiva pressupóe competências ou a necessidade de satisfazer determinadas exigências; ela emerge de disposições históricas, tradicionais, morais, normativas, estipuladas pelos "eus" que a constituem. Uma forma tradicional de reconhecimento jurídico dessa espécie já concede a todo "eu" uma proteção social para sua "dignidade" humana; mas esta não parece dependente da condição de eus cujas consciências morais apresentam-se em estágio pós-convencional. Ao contrário, ao que tudo indica, tal produção está ainda inteiramente fundida com o papel social que compete a cada eu, no quadro de uma distribuiçáo de direitos e encargos amplamente desigual, porque baseado mais na tradição, no hábito, que em princípios universalistas. Isso não foi pontuado por Habermas, e se contrapóe ao seu próprio entendimento segundo o qual deliberaçôes concernentes à pretendida aplicação de qualquer norma não derivarão de consideraçóes de índole claramente contextual, as quais possam contradizer o enorme esforço realizado para obter uma fundamentação de tipo universal.

Percebe-se alhures o não entrelaçamento entre princípio do discurso e o próprio do aparato jurídico, de maneira que também aquela indeterminação cognitiva do cidadáo comum é absorvida "[...] pela faticidade da imposiçáo do direito", tendo, no legislador político, aquele que decide sobre as normas que devem valer como direito e, nos tribunais, a instância que, embora sem possuir a última palavra, pode resolver possíveis disputas a respeito da aplicaçáo de normas validadas. ${ }^{31} \mathrm{E}$ uma vez que, numa sociedade complexa, é impossível a participação efetiva de todos os envolvidos no processo de elaboração da lei, esse modelo parece resvalar para a idealidade, visto tal participação dever ser

${ }^{31}$ FG 147, t. 151 v. I; 670 , t. 315 v. II. 
ao menos potencialmente possível, pois que estipula: a inclusão ideal de todos os falantes; a verificabilidade das normas como sua condição de legitimidade. No concernente a isso, Habermas é claro: esses artifícios se complementam na produção legislativa da norma jurídica. Se, em 1991, com Comentários à ética do discurso, a estrutura argumentativa sustenta-se na defesa da comunidade hermenêutica que, mediante praxis discursiva, implanta normas capazes de transcender seu espaço e tempo limitados, nessa mesma década, um ano após, a filosofia do direito cerca esse exercício, desloca-o do mundo da vida e subordina-o a um subsistema de poder, ainda que este seja um modelo ideal, porque pública, de esfera jurídica. E isso indica que o esforço do filósofo de idealização vai gradativamente se aproximando do empírico, muito embora neste século atual sua produção a esse respeito mantenha a base ideal como pano de fundo dos argumentos e análises que desenvolve acerca dos direitos humanos. ${ }^{32}$

MARTINS, Clélia Aparecida. Norms and the establishment of human rights. Trans/Form/ Ação, Marília, v. 36, p. 121-148, 2013. Edição Especial.

\begin{abstract}
Habermas understands human rights as products of the lifeworld, and it is within the public debate, with the effective participation of citizens, that their production must occur as norms and principles. The initial focus of the text concerns the status of these norms and how they are instituted, which depends on the reciprocal relationships between subjects. Given that in complex societies it seems to be only ideally possible to sustain the participation of all those involved in the elaboration of norms, this article seeks to analyze the feasibility of Habermas' conception. In considering the conceptual elements related to this issue, there takes place in the course of the text a shift to another issue, namely, that of how the mode of support of the juridical normativity of a legal order determines it as being democratic or not. This is the turning point in the treatment of norms relative to human rights: Habermas' analysis is ideal, but the oscillation between the moral and the empirical is always remains, such that, within the conceptual scope, if there is no way to confirm the legitimacy of the identification of human rights with democratically produced human rights, this oscillation becomes impossible deny.
\end{abstract}

KEYWORDS: Jürgen Habermas. Human rights. Norms. Reciprocity.

\footnotetext{
32 Sobre isso, ver o primeiro capítulo de Zur Verfassung Europas (2011), no qual Habermas estabelece um paralelo entre a história dos direitos humanos e o papel do conceito de dignidade humana.
} 


\section{REFERÊNCIAS}

BAL, Peter. Discourse ethics and human rights in criminal procedure. Philosophy \& Social Criticism, v. 20, no 4, p. 72-99, 1994.

DWORKIN, R. Law's Empire. Cambridge: Belknap, 1986.

FORST, R. Das grundlegende Recht auf Rechtfertigung. In: BRUNKHORST, H. et al. Recht auf Menschenrechte - Menschenrechte, Demokratie und internationale Politik. Frankfurt am Main: Suhrkamp, 1999, p. 66-105.

GEHARDT, V. Menschenrechte und Rhetorik. In: BRUNKHORST, H. et al. Recht auf Menschenrechte - Menschenrechte, Demokratie und internationale Politik. Frankfurt am Main: Suhrkamp, 1999, p. 20-40.

HABERMAS, J. Entgegnung. In: HONNETH, A.; JOAS, H. (Org.). Kommunikatives Handeln. Frankfurt am Main: Suhrkamp, 1986, p. 327-405.

Die Einbeziehung des Anderen: Studien zur politischen Theorie. 2. Aufl. Frankfurt am Main: Suhrkamp, 1999 [Trad. George Sperber e Paulo Astor Soethe. A inclusão do outro. São Paulo: Loyola, 2002). [EA]

. Erläuterungen zur Diskursethik. Frankfurt am Main: Suhrkamp, 1991 [Trad. Gilda Lopes Encarnação: Comentários à ética do discurso. Lisboa: Instituto Piaget, 1999]. [ED]

Faktizität und Geltung. Beiträge zur Diskurstheorie des Rechts und des demokratischen Rechtsstaats. 4. Auflage, Frankfurt am Main: Suhrkamp, 1994. [Trad. Flávio Beno Siebeneichler: Direito e democracia: entre faticidade e validade. Rio de Janeiro: Tempo Brasileiro, 1997, 2 vols.] [FG]

Legitimationsprobleme im Spätkapitalismus. 5. Auflage, Frankfurt am Main: Suhrkamp, 1979 [Trad. Vamireh Chacon: A crise de legitimação do capitalismo tardio. Rio de Janeiro: Tempo Brasileiro, 1980]. [LS]

. Moralbewusstsein und kommunikatives Handeln, Frankfurt am Main: Suhrkamp, 1983 [Trad. Guido A. Almeida: Consciência moral e agir comunicativo, Rio de Janeiro: Tempo Brasileiro, 1989]. [MkH]

. Die neue Unübersichtlihkeit. Frankfurt am Main: Suhrkamp, 1988. [NU]

Der philosophische Diskurs der Moderne. Frankfurt am Main: Suhrkamp, 1985

[O Discurso Filosófico da Modernidade: doze liçōes. Trad.: Luis Sérgio Repa e Rodnei Nascimento. São Paulo: Martins Fontes, 2000]. [PDM]

Die postnationale Konstellation - politische Essays. Frankfurt am Main: Suhrkamp, 1998 [Trad. Márcio Seligmann-Silva: A constelação pós-nacional, São Paulo: Littera Mundi, 2001]. [PK]

. Zur Rekonstruktion des historischen Materialismus. 2. Auflage, Frankfurt am Main: Suhrkamp, 1976 [Trad. Carlos Nelson Coutinho: Para a reconstrução do materialismo histórico, São Paulo: Editora Brasiliense, 1990]. [ZRhM] 
Zur Verfassung Europas. Frankfurt am Main: Suhrkamp, 2011 [Trad. Denilson L. Werle, Luiz Repa e Rúrion Melo: Sobre a constituição da Europa. São Paulo: Editora da UNESP, 2012].

. Theorie des Kommunikativen Handelns, Frankfurt am Main: Suhrkamp, vol. 2, 1987. [TkH]

KNEER, G. Die Pathologien der Moderne. Opladen: Westdeutscher Verlag, 1990.

MAUS, I. Die Trennung von Recht und Moral als Begrenzung des Rechts. Rechtstheorie, 20, 191-210, 1989. 
MARTINS, C. Ap. 